UDC 613.632.2

DOI: $10.21668 /$ health.risk/2019.3.19.eng

\title{
MODERN ASPECTS OF REGULATORY, PATHOPHYSIOLOGICAL AND TOXIC EFFECTS OF COBALT IONS DURING ORAL INTAKE IN THE HUMAN BODY
}

\author{
S.I. Dolomatov ${ }^{1}$, T.P. Sataeva ${ }^{1}$, W. Zukow ${ }^{2}$ \\ ${ }^{1}$ Medical Academy named after S.I. Georgievsky of Vernadsky Crimea Federal University, 5/7 Lenin Boulevard, \\ Simferopol, 295006, Russian Federation jurisdiction \\ ${ }^{2}$ Universitas Nicolai Copernici, 1 Lwowska Str., 87-100 Toruń, Poland
}

Cobalt is an essential microelement which is an indispensable part of several enzymes and co-enzymes. Cobalt ions may occur in the environment from both natural sources and due to human activities. This metal is very widespread in the natural environment and can be formed due to anthropogenic activity. Toxic effects produced by cobalt and its compounds depend on the physical and chemical properties of these complexes, including their electronic structure, ion parameters (charge-size relations) and kinetics. Cobalt has both beneficial and harmful effects on human health. Cobalt is beneficial for humans because it is a part of vitamin $B_{12}$, which is essential to maintain human health. If humans and animals are exposed to levels of cobalt normally found in the environment, it is not harmful. When excessive cobalt amounts enter a human body, multiple and chronic harmful health effects can occur and the longer the cobalt ions are stored in the body, the more changes they cause in cells. Cobalt gets into a body via several ways: mainly with food, via the respiratory system, through the skin or as a component of various biomaterials. Despite this metal being abundant, much of our knowledge on cobalt toxicity is based mainly on studies performed on animals. Undoubtedly, inorganic forms of cobalt are toxic as they accumulate in various tissues and can evoke a chain of pathological cascade changes in cells. Although some cobalt effects might be beneficial for medicine. Therefore, the purpose of our review is to provide the current analysis about the most significant regulatory, pathophysiological and epigenetic effects of $\mathrm{Co}^{2+}$ in a human body.

Key words: cobalt, $\mathrm{Co}^{2+}$ salts, $\mathrm{Co}^{2+}$ kinetics, heavy metal, cobalt toxicology, pathophysiology, epigenetics.

Introduction. The environmental pollution with xenobiotics is one of global unresolved problems, the relevance of which increased even more in the 21 st century. Among modern xenobiotics the leading position is occupied by salts of heavy nonferrous metals, which are extracted in large quantities into the human habitat. These include toxic trace elements such as: lead, cadmium, cobalt, chromium, mercury, aluminum, etc. Heavy nonferrous metals enter a body not only through the gastrointestinal tract, which is most vulnerable to effects produced by man-made exotoxicants, but also through the respiratory organs, integuments and mucous membranes, especially with decreased barrier functions.

According to the modern data rather high bioavailability of cobalt salts and the presence of metal mineral compounds in human trophic chains can be caused by both endemic geochemical factors and the human activity itself associated with the operation of coal-fired power plants, the production of certain foods, the mining and processing of metals, medical alloys, ceramics, household

(C) Dolomatov S.I., Sataeva T.P., Zukow W., 2019

Sergei I. Dolomatov - Candidate of Medical Sciences, Associate Professor at Department of Biology кафедры биологии (e-mail: path888d@yandex.ru; tel.: +7(3652)554-911; ORCID: https://orcid.org/0000-0001-7422-5657).

Tat'yana P. Sataeva - Candidate of Medical Sciences, Associate Professor at Department of Biology (e-mail: tanzcool@mail.ru; tel.: +7(3652)554-911; ORCID: https://orcid.org/0000-0001-6451-7285).

Walery A. Zukow - Candidate of Medical Sciences, Associate Professor at Faculty of Earth Sciences (e-mail: w.zukow@wp.pl; tel.: +48-601-92-55-95; ORCID: https://orcid.org/0000-0002-7675-6117). 
waste disposal, etc. There are numerous available data indicating a role diet plays in the intensity of cobalt entry into a human body [1-4]. The results of kinetics research on the bivalent cobalt ions $(\mathrm{Co} 2+)$ in a human body demonstrate that the maintenance of stable systemic indicators of this ion can be enhanced by binding the cation to plasma polyanion proteins (e.g. albumin); accumulation of significant amounts of $\mathrm{Co} 2+$ inside erythrocytes; its intense reabsorption by tubular nephron epithelium. The predominant pathways for cobalt excretion out of a human body or other mammals' ones are the kidneys and the gastrointestinal tract. The intensity of renal clearance of $\mathrm{Co} 2+$ rather accurately reflects the balance of the soluble ion fraction in the extracellular body fluid. A modern methodology for estimating the level of cobalt consumption by people can be based on analysis of the Co2+ dynamics in blood and urine [5-7]. Along with this, in population studies it is quite interesting to compare the dynamics of cobalt content in various human blood and hair samples. The parallel between the metabolic pathways in a human body of the $\mathrm{Ca} 2+$ and $\mathrm{Co} 2+$ cations is emphasized suggesting a preferential distribution of those cations in the intravascular fluid, in erythrocytes and in specialized cellular organelles of certain tissues with high rates of $\mathrm{Ca} 2+$ metabolism [8]. In particular, in experiments conducted on rats the cardiotoxic effect of bivalent cobalt salts was demonstrated mainly due to the accumulation of the $\mathrm{Co} 2+$ cation inside the cardiomyocytes. On the other hand, experimental evidence is given for the thesis stating that the intracellular metabolism of $\mathrm{Co} 2+$ may be closely linked with the metabolism of $\mathrm{Zn} 2+$ ions and the transport system of positively charged aminoacids through cationic amino acid transporter - Cat1 [9].

There are several reasons why the development of effective methods for assessing the levels of $\mathrm{Co} 2+$ intake and the study of its kinetics in a human body can have practical importance. Firstly, physiologically active $\mathrm{Co} 2+$-containing complex compounds (cobalamins) are vital for the normal biochemistry of physiological processes. Secondly, cobalt mineral salts $(\mathrm{Co} 2+)$ are constantly present in food products, mainly of animal origin (EFSA Panel on Additives, 2009). The obtained data suggest that a permissible daily intake of $\mathrm{Co} 2+$ into a human body may be limited up to $1,000 \mu \mathrm{g} /$ day. According to other data, a permissible daily intake dose for $\mathrm{Co} 2+$ is about $600 \mu \mathrm{g} /$ day (EFSA Panel on Additives, 2009). The existing sanitary norms of the Republic of France stipulate the limiting values of the permissible daily consumption of $\mathrm{Co} 2+$ (depending on age), which are 1.6-8 $\mu \mathrm{g} / \mathrm{kg}$ bw / day [10]. Given that normal food intake of cobalt ions is, on average, $0.012 \mathrm{mg}$ day -1 per person, reaching higher values in some populations of India $0.23 \mathrm{mg}$ day -1 and Japan $0.036 \mathrm{mg}$ day -1 . Excessive physiological norms of oral consumption of $\mathrm{Co} 2+$ can cause toxic effects, activating the processes of mutagenesis, carcinogenesis and tissue necrosis through the induction of reactive oxygen species formation and suppressing the work of DNA repair systems [11-13], activation of pro-inflammatory factor products, thyroid dysfunction, increased risk of cardiomyopathy, encephalopathy and congenital birth defects [14-16]. The obtained data from population-based studies confirm that higher levels of cobalt intake into a human body may lead to a decrease in visual acuity [17].

In humans as well as in other mammals the mineral salts of $\mathrm{Co} 2+$ do not participate in the processes of biosynthesis of cobalamins by the intestinal microflora. At the same time we have obtained some data reports indicating that $\mathrm{Co} 2+$ ions coming from food (not included in cobalamins) can cause regulatory effects mediated by the production of physiologically active substances that act as a kind of cation mediators in relation to various tissues and organs. Primarily, these effects are related to hypoxia-inducible 
factor (HIF) [18-21]. Meanwhile, that particular influence of cobalt on a body which is mediated through the hypoxia-inducible factor does not entirely correspond to the generally accepted views on the toxic effects of cobalt substances. Perhaps, therefore, over the past two decades, this line of research has quite clearly transformed into an independent research direction. The presence of its own specific approaches and research methods allows it to productively bring about a range of issues concerning the pathophysiological and regulatory aspects of the $\mathrm{Co} 2+$ influence on a human body. In our opinion, this is the most promising and relevant direction for both fundamental science and practical medicine.

Consequently, the purpose of our data analysis is to provide the current information about the regulatory and pathophysiological effects of $\mathrm{Co} 2+$ in a human body regarding the systemic, tissue and molecular levels after toxic food intake or during accumulation of the cobalt cation in the extracellular body fluid.

Toxic effects of cobalt. In the context of the facts under consideration, information on the pronounced direct toxic effects of cobalt can appear to be rather interesting because it allows to make a clearer distinction between the mechanisms of the regulatory and toxic effects of $\mathrm{Co} 2+$. It should be noted that the origin of the toxic effects and the level of the toxic dose of cobalt cation largely depend on the way how it enters the body: orally, inhaled, or through the skin. According to some authors, the threshold values of its oral intake were identified, the excess of which causes a toxic effect. In particular, for oral administration of $\mathrm{Co} 2+$, the minimum risk threshold is associated with daily ion intake of about $0.01 \mathrm{mg} \mathrm{Co} / \mathrm{kg}$ body weight / day. The review shows that induced $\mathrm{Co} 2+$ cardiomyopathy can be caused by food intake of an ion within 0.04 to 0.14 $\mathrm{mg} \mathrm{Co} / \mathrm{kg} /$ day. There is an opinion on the relevance of studies aimed at substantiating the threshold levels of $\mathrm{Co} 2+$ compounds in a human body since the proportion of anthropogenic factor in the bioavailability of this chemical element for humans has significantly increased. It has been suggested that the threshold values of the systemic toxic effects of $\mathrm{Co} 2+$ may be due to the saturation of the intravascular deposition systems of the cation (plasma proteins and erythrocytes) and an increase in the concentration of free [22].

Hence, not only the levels of food intake of metal ions, but the state, for example, of protein metabolism, can determine the degree of $\mathrm{Co} 2+$ toxicity. Indeed, there are direct evidences that a low protein diet can be considered as an additional risk factor for the development of the toxic effects produced by $\mathrm{Co} 2+$. The results of clinical studies also confirmed the ability of plasma proteins to bind $\mathrm{Co} 2+$ ions, emphasizing the possible role of this mechanism in neurotoxic effects produced by metal cations.

The available data suggest that the direct toxic effects of $\mathrm{Co} 2+$ on humans and animals occur mainly due to the elevation of reactive oxygen species resulting in the activation of lipid peroxidation and proteins, followed by severe destructions of nucleic acids and the suppression of DNA repair systems [23]. It is indicated that the application of antioxidants reduces the toxic effect of cobalt [24]. The authors of the cited review indicate that not only salts, but also metallic cobalt possess genotoxic properties, while cobalt compounds, for example, with tungsten or tungsten carbide, can enhance their genotoxic and carcinogenic properties.

Meanwhile, there is some evidence that direct damage to mitochondria can be considered as another pathogenetic mechanism of polyorganic disorders induced by cobalt salts [25]. According to the authors of the cited publication, the toxic effect of $\mathrm{Co} 2+$ on mitochondria contributes to the development of oxidative stress and damage to mitochondrial DNA regardless of the nuclear DNA 
damage. In vitro studies on murine embryonic stem cells revealed that cobalt dichloride $\mathrm{CoCl} 2$ enhanced the formation of reactive oxygen species, reduced the level of antioxidant defense, promoted the release of cytochrome $\mathrm{C}$ from mitochondria into the cytoplasm and finally activated mitochondrial cell apoptosis [26]. The authors highlighted that toxic effects of cobalt dichloride depended on a dose and a time period during which cells were exposed to a medium containing heavy metal ions. It was reported that cobalt dichloride was able to induce the formation of a superoxide anion in the mitochondria of various human cells [27].

In our opinion, it should be taken into account that the toxic levels of $\mathrm{Co} 2+$ can have a specific effect on the immune system. In particular, studies on human monocytes and neutrophils in vitro have shown that $\mathrm{Co} 2+$ cations activate the Toll-like receptor4 (TLR4) of leukocytes, stimulating cell migration, resulting in increased production of pro-inflammatory cytokines and the formation of foci of infiltrates [28]. On the other hand, the induced by $\mathrm{Co} 2+$ Toll-like receptor-4 is expressed on the human microvascular endothelial cells [29]. So, the cited results go in a good agreement with the previously obtained information about $\mathrm{Co} 2+$-dependent induction of TLR4 in murine peritoneal macrophages is accompanied by the overproduction of pro-inflammatory cytokines and tissue hormones [30].

Nevertheless, the analysis of the toxic properties that a substance might have should be always based on research on its kinetics in a human body. On one hand, a number of organs (myocardium, liver, kidneys) with the ability to accumulate $\mathrm{Co} 2+$ ions have been identified. There is indication of a change in metabolic processes in the liver and kidneys of rats exposed to prolonged exposure to cobalt dichloride in a dose equal to $12.5 \mathrm{mg}$ cobalt $\mathrm{kg}-1$ for 7 days [31]. Pathomorphological studies have shown that cobalt dichloride leads to dose-dependent structural disorders in the liver and myocardial tissue [32]. In the context of the previously discussed issues, it is important to emphasize that the tissues characterized by a high intensity of $\mathrm{Ca} 2+$ metabolism can be considered as a target for the toxic effects of $\mathrm{Co} 2+$. Indeed, the results of experimental studies suggest that salts of $\mathrm{Co} 2+$ triggered the necrotic changes in the heart and kidneys [33]. Skeletal musculature can be also considered as a $\mathrm{Co} 2+$ target organ. It has been established that Bcl-2 adenovirus E1B interacting protein-3 (BNIP3) is an important component in muscle tissue, determining $\mathrm{Co} 2+$-induced autophagy via the HIF - BNIP3. In connection with these facts, information about the mechanisms of $\mathrm{Co} 2+$ ion entry into a cell and into its mitochondria can be quite helpful. Divalent metal ion transporter 1 (DMT1) is considered to be the main channel of $\mathrm{Co} 2+$ entry (as well as divalent ions of iron and nickel). However, it is reported that the transport of the histidine aminoacid through the cationic aminoacid transporter Cat 1 can also be involved in the absorption of cobalt cations, whereas the Zhfl transport protein, which is responsible for the metabolism of zinc ions, can detoxify cells from cobalt cations. According to the current references, the further entry of the $\mathrm{Co} 2+$ from the cytoplasm into the mitochondrial matrix is carried out according to the equivalent transport mechanism of $\mathrm{Ca} 2+$ and other bivalent metal ions - the mitochondrial permeable transitional pore mechanism mediated by the mitochondrial potential [34]. In addition, the authors draw attention to the fact that $\mathrm{Co} 2+$ ions alike $\mathrm{Ca} 2+$ ions, can influence the system of mitochondrial translocations.

On the other hand, the results of in vitro studies on the culture of cardiomyocytes made it possible to establish that the toxic properties of cobalt dichloride occurred due to a direct toxic effect on the state of redox processes in mitochondria that triggered the cell apoptosis [35]. Perhaps a feature of the cardiotoxic action of $\mathrm{Co} 2+$ is the disruption 
of the fundamental processes of energy metabolism in mitochondria which are not capable to maintain the adequate contractile functions of cardiomyocytes affecting both systole and diastole [36]. Arguments confirming damage to mitochondria by cobalt $(\mathrm{Co} 2+)$ ions of the tricarboxylic acid cycle [37] are also being discussed. In vitro studies have established that cobalt dichloride stimulates oxidative stress and apoptosis in a dose-dependent manner [38]. The authors showed that $\mathrm{Co} 2+$ ions stimulated the expression of dynamin-related protein 1 (Drp1), which determined the pathogenetic mechanisms of cell death: a decrease in the mitochondrial membrane potential, a decrease in ATP level, the stimulation of the formation of reactive oxygen forms. The mechanisms of cell apoptosis caused by mitochondrial damage and excessive stimulation of oxidative stress are considered to be the universal pathogenetic mechanism of $\mathrm{Co} 2+$ induced damage to the central nervous. It is also impossible to exclude the fact that a synergistic factor determining the nature of the influence of cobalt dichloride on the fundamental metabolic processes (Krebs cycle activity, electron transport rate by cytochromes and mitochondrial DNA transcription activity) in the mitochondria can be considered as a hypoxia-inducible factor [39].

Nowadays attention is drawn to the fact that most authors, discussing the toxic effect of $\mathrm{Co} 2+$ on mitochondria, point to increased production of reactive oxygen species and the induction of apoptosis, as two closely related effects. Meanwhile, there are reports in the literature that such close relationship between oxidative stress and apoptosis is more typical for the pure metallic cobalt [40]. At the same time, the authors of the cited publication provide the data that the path of stimulation of apoptotic signals by $\mathrm{Co} 2+$ ions may not be directly related to the activation of oxidative stress.

Pathophysiological effects of Co2+. An important aspect of the problem under discussion is that cobalt mineral salts, those which are not part of cobalamins, can have their own regulatory effect on the state of metabolic processes in a human body. Cobalt salts $(\mathrm{Co} 2+)$ have been used for a long time as a pharmacological stimulators of hematopoiesis in the treatment of anemias [41, 42]. Further studies have shown that hypoxiainducible factor is the leading mediator that determines the pathway and intensity of the effects of cobalt mineral salts on a human body. The question regarding the feasibility of pharmacological treatment of anemia with cobalt hematopoietic salts was withdrawn from wide practical application in the 70 s of the 20th century. Meanwhile, the possible aspects related to using cobalt mineral salts, mainly in the form of $\mathrm{Co} 2+$ still remain in the field of interests of modern practical medicine and is reflected in a number of modern publications.

According to the modern references the hypoxia-inducible factors are considered to be the main mediators of the regulatory and pathophysiological effects of the $\mathrm{Co} 2+$ salts. An analysis of the possible mechanisms of Co2+-dependent induction of hypoxia-inducible factors allowed to express the opinion that the suppression of the metabolic clearance of HIF-1 $\alpha$ as a result of $\mathrm{Co} 2+$-induced decrease in the enzymatic activity of prolyl hydroxylases was not likely to be associated with the replacement of the $\mathrm{Fe} 2+$ ion with $\mathrm{Co} 2+$ in the enzyme catalytic center $[43,44]$. According to the authors of the cited publications, the more likely mechanism of $\mathrm{Co} 2+-$ dependent stabilization of HIF-1 $\alpha$ is depletion in the presence of $\mathrm{Co} 2+$ ions of intracellular reserves of ascorbic acid, which is crucial for the reduction of $\mathrm{Fe} 3+$ to $\mathrm{Fe} 2+$ in the active center of prolyl hydroxylases. Some data represents the role of $\mathrm{Co} 2+$ in the metabolic clearance of HIF-1 $\alpha$ with the participation of von Hippel-Lindau protein [45], as well as in the stimulation of HIF-1 $\alpha$ translation.

However, by analyzing the effects produced by $\mathrm{Co} 2+$ salts bounded with the stabi- 
lization of HIF-1 $\alpha$, a unique pattern can be revealed that is not observed during review the basic pathogenetic mechanisms of the toxic effects produced by this metal. Firstly, the direct toxic effects of $\mathrm{Co} 2+$ mineral salts are considered as a uniquely negative factor. At the same time, in the case of low levels of $\mathrm{Co} 2+$ intake not exceeding the toxic threshold values, in addition to negative body reactions, we can observe physiological effects which are potentially applicable in practical medicine. For example, in earlier studies it was suggested that cobalt dichloride could serve as a promising adaptogen in the conditions of hypobaric hypoxia [46]. The results of later studies show the promising outcomes of cobalt in vitro application in regenerative medicine in order to: form HIF-1 $\alpha$-dependent $\mathrm{Co} 2+$ induce stem cells of a certain phenotype [47], create conditions that are optimal for implant engraftment [48] and to control osteogenic differentiation [49]. Along with this, promising results on nephroprotective properties of cobalt salts were obtained in in vivo studies $[50,51]$. Considering the previously identified HIF-1 $\alpha$ dependent nephroprotective properties of $\mathrm{Co} 2+$, the use of organometallic cobalt complexes has been proposed, which are able to provide strictly supervised intrarenal level of $\mathrm{Co} 2+$ production in order to inhibit interstitial fibrosis.

Secondly, the ability of $\mathrm{Co} 2+$ ions to stabilize HIF-1 $\alpha$ is considered to be a pleiotropic pathophysiological mechanism of cation influence associated with producing various physiologically active molecules and affecting the mitochondrial function. In regard to this statement, the warnings that cobalt mineral salts are not the mandatory component of human diet and their food consumption should be strictly standardized are absolutely reasonable. Indeed, research results show that even relatively low levels of cobalt dichloride intake can cause vivid changes in metabolic processes in the myocardium and in the renal parenchyma [52]. It was also established that cobalt dichloride even in the low doses not exceeding the toxic threshold, may trigger the tissue fibrosis and necrosis [53].

In earlier publications, there is evidence of demand for biomonitoring of the presence of $\mathrm{Co} 2+$ in human food, emphasizing the versatility of such pathophysiological reactions, such as inflammation, in response to the presence of a cation in the body [54]. Also, it is necessary to point out that the authors of the cited reviews emphasize the role of HIFs proteins in the realization of the pathophysiological effects produced by cobalt. It is possible that a more significant range of pathophysiological reactions to intake of $\mathrm{Co} 2+$ can be related to a number of HIF-1 $\alpha$-dependent regulatory effects of $\mathrm{Co} 2+[55,56]$. In particular, it is indicated that inflammation can be considered as one of the pathogenetic HIF- $1 \alpha$-related effects of hypoxia. There are also grounds to believe that $\mathrm{Co} 2+$ ions stimulate the expression of the cyclooxygenase- 2 protein gene, against the background of a decrease in the enzymatic activity of endothelial NO-synthase complexes [57]. In vitro studies have shown that $\mathrm{Co} 2+$ have the ability to activate the biosynthesis of inducible NO synthase and pro-inflammatory interleukins in macrophages. A number of publications emphasize the universal pathogenetic role played by the Toll-like receptor-4 (TLR4) of leukocytes in body's immune responses to salts of heavy metals such as cobalt and nickel [58]. It is interesting that nanoparticles of metallic cobalt can also stimulate the dose-dependent production of human monocytic IL-1 $\beta$ and TNF- $\alpha$ [59]. The authors of the cited publications also provide facts confirming the role of the pro-inflammatory effect produced by cobalt and its compounds in the pathogenesis of the immunopathologies in muscular and bone tissues. However, there is evidence in the literature that cobalt dichloride can induce immunosuppression by suppressing the action of pro-inflammatory factors [60]. 
Although, as we have already observed, the regulatory effects of the metal may depend on the dose of exposure and some other experimental conditions.

At the same time, it has been shown that cobalt salts in the liver, in subtoxic concentrations, can stimulate the production of a transforming factor beta-pleiotropic cytokine, which determines cell cycle restriction, stimulation of extracellular matrix protein synthesis combined with immunosuppressor effects. The authors of the cited source believe that the dynamics of TGF-beta production reflects the risk of organ fibrosis and can act as the cancerogenic factor. Attention is drawn to the fact that $\mathrm{Co} 2+$-induced fibrosis may be systemic and get triggered by the generation of reactive oxygen species, while the another heavy metal chromium ions $(\mathrm{Cr} 3+)$ do not act this way $[61,62]$.

Discussing HIF-1 $\alpha$-dependent regulatory effects of $\mathrm{Co} 2+$ in our consideration, it is necessary to point out another important area of research due to the ability of the metal to participate in the regulation of gene expression through such mechanisms as covalent chromatin modification and synthesis of small non-coding RNA. This line of research is developing dynamically in the field of testing new diagnostic methods, and is also valuable in developing a fundamentally new way to treat the most lethal cancer cases [63-65].

Epigenetic effects of $\mathbf{C o 2}+$. The earliest publications on this topic contain information that $\mathrm{Co} 2+$ can stimulate the transcription of certain proteins independently of the intracellular endogenous production of reactive oxygen species. Further, directly induced by $\mathrm{Co} 2+\mathrm{HIF}-1 \alpha$-dependent epigenetic mechanisms associated with enzyme DNA methylation and histone acetylation systems were evidenced. In the modern reviews the role of epigenetic mechanisms in the implementation of toxic and carcinogenic effects of heavy metals is widely emphasized [66-69]. The importance of the HIF-1 $\alpha$-dependent epigenetic mechanisms induced by cobalt and other heavy metals is also recognized. It was also shown that stimulation of cobalt dichloride with extracellular matrix deposits, as well as induction of vascular endothelial growth factor and erythropoietin were associated with HIF-1 $\alpha$ [70]. In our opinion, the scientific novelty of the proposed approach consists in the fact that for the first time the pathogenesis of deadly oncological diseases induced by heavy metals was explained and based on epigenetic mechanisms for controlling of gene expression. At the same time, the pathogenesis of these diseases was not considered as a result of direct DNA damage $[71,72]$. The developed approach was based on the carcinogenic effects produced by heavy metals and caused by a specific covalent modification of chromatin that alters gene expression. The sustainability of this approach was confirmed by subsequent research results [73].

The results of in vitro studies on cell culture of multiple myeloma (B-cell malignancy selectively localized in the bone marrow) showed that the presence of cobalt chloride had a significant effect on the levels of HIF- $1 \alpha$ in cells, as well as on the state of expression of the genes identified as transcription factors, cell differentiation markers, protein kinases, cytokines and growth factors, tumor suppressors, and oncogenes $[74,75]$. According to the authors, they managed to isolate a group of genes sensitive to $\mathrm{Co} 2+$ ions. It was also established that cobalt dichloride, through the processes of acetylation of histone proteins, regulates the expression of extracellular-superoxide dismutase [76]. On the other hand, valproic acid, and histone deacetylase inhibitors, has been shown to reduce the pathophysiological effects of HIF-1 $\alpha$ [77].

Along with this, it was shown that HIF$1 \alpha$ can regulate not only the covalent modification of chromatin, but also affect the biosynthesis of small non-coding RNAs capable of determining protein biosynthesis at the 
level of transcription or translation. Indeed, there is evidence in the literature that HIF may influence the metabolic systems of noncoding small RNAs [78]. At the same time, in vitro studies have established a link between the presence of cobalt in a medium, HIFs with proteins, and the expression index of micro RNA cells. There is evidence that HIF-dependent mechanisms, through the micro-RNA system, are involved in the regulation of the expression of pro-inflammatory cytokines. The mechanisms of $\mathrm{Co} 2+$ inflammation induction play an important role in the pathogenesis of cobalt intoxication, however, the role of epigenetic mechanisms that determine the synthesis (including micro RNA) of pro-inflammatory protein factors has not been studied deeply enough.

Conclusions. The relevance of studying the kinetics of heavy non-ferrous metals coming from the industrial objects is determined by significant pollution of the modern ecosystems. Ecotoxicants affect all internal organs at the molecular, cellular, tissue and systemic levels. The toxic effect of the damaging factor depends on its concentration and exposure duration, its combination with the other damaging factors, chronic human diseases and its immunological reactivity.

One of the representatives of heavy nonferrous metals is cobalt, which simultaneously belongs to the group of microelements and therefore is vital for the functioning of living organisms, but at the same time, with its increased intake, it is toxic to a body and even destructive. There are certain concentrations in which cobalt is essential for living organisms. The main biological role of this element is its presence in the molecule of water-soluble vitamin B12 (cyancobalamin), in which its mass fraction is $4 \%$. However, excessive intake of cobalt in a body is geno-, enzyme-and membrane-toxic. The toxicity of cobalt in high concentrations occurs due to its hypoxic action, activation of lipid peroxidation and depletion of antioxidant systems. Cobalt, as an ion with variable valence, se- verely induces lipid peroxidation, promotes the formation of oxidative stress, which disrupts the function of the endothelium, damages biological macromolecules of internal organs: respiratory organs, cardiovascular system, liver and especially kidneys, where xenobiotics are neutralized.

The data from a number of studies indicate a toxic effect produced by cobalt chloride on the kidneys and myocardium, characterized by the development of microangiopathy, fibrotic proliferation, stimulation of apoptosis and even necrosis. The basis of the toxic effect produced by heavy nonferrous metal salts, including cobalt, is the development of oxidative stress that can damage the cell and mitochondrial membranes and cause their structural and functional changes. The blocking of functionally active groups, structural proteins and functioning enzymes plays a significant role in the development of these disorders. Another mechanism of the toxic effect of heavy metals on the body is their ability to replace calcium ions in specific processes.

The toxic effect produced by cobalt has been studied many times and has already been proven, however the mechanisms of the damaging effect produced by cobalt at the molecular and DNA level have not yet been fully studied. Cobalt dichloride ( $\mathrm{CoCl} 2)$ has a similar effect to hypoxia due to expression of HIF-1 $\alpha$ mRNA, which indicates the dependence of the expression process of this mRNA not only according to oxygen level, but also in the presence of iron ions. Cobalt is able to firmly bind with heme than iron. It was also shown that cobalt activates HIF-1 due to depletion of the intracellular content of ascorbic acid, a co-factor for HIF-hydroxylase, which destabilizes and inactivates HIF-1 $\alpha$. Hypoxia is known to be a typical pathological process that accompanies and determines the development of many pathological conditions. It leads to functional, and then structural changes in organs and tissues as a result of a decrease in the intracellular 
concentration of oxygen. This also applies to hypoxia of tumor cells (intratumoral hypoxia). Thus, many cancers include areas of hypoxia. Intratumoral hypoxia significantly worsens the forecast of the disease, since angiogenesis in the tumor tissues is very intense. This, apparently, is one of the reasons for the rapid growth of malignant tumors and can explain cancerogenic cobalt effect. In addition, enhanced angiogenesis in the tumor contributes to the metastasis of its cells, which ultimately increases mortality among such patients. The principal mechanism with which cancer cells adapt to hypoxia is activation of the HIF-1 factor. The elucidation of the pathogenetic role played by the HIF-1 $\alpha$ factor opens up new possibilities not only in the correction of hypoxia, but also in the treatment of malignant tumors.

As illustrated, the influence of cobalt ions on a body should be researched deeply, as well as interactions between cobalt and other ions and aminoacids occurring in body fluid. Perhaps these interactions can also have some specific and significant beneficial effects.

Funding. The research was not granted any sponsor support.

Conflict of interests. The authors state there is no any conflict of interests.

\section{References}

1. Hokin B., Adams M., Ashton J., Louie H. Comparison of the dietary cobalt intake in three different Australian diets. Asia. Pac. J. Clin. Nutr., 2004, vol. 13, no. 3, pp. 289-291.

2. Gál J., Hursthouse A., Tatner P., Stewart F., Welton R. Cobalt and secondary poisoning in the terrestrial food chain: Data review and research gaps to support risk assessment. Environment International, 2008, no. 34, pp. 821-838. DOI: 10.1016/j.envint.2007.10.006

3. Scientific Opinion on the use of cobalt compounds as additives in animal nutrition. EFSA Panel on Additives and Products or Substances used in Animal Feed (FEEDAP). EFSA Journal, 2009, vol. 7, no. 12: 1383, 45 p. DOI: $10.2903 /$ j.efsa.2009.1383

4. Tvermoes B.E., Paustenbach D.J., Kerger B.D., Finley B.L., Unice K.M. Review of cobalt toxicokinetics following oral dosing: Implications for health risk assessments and metal-on-metal hip implant patients. Crit. Rev. Toxicol., 2015, vol. 45, no. 5, pp. 367-387. DOI: $10.3109 / 10408444.2014 .985818$

5. Tvermoes B.E., Unice K.M., Paustenbach D.J., Finley B.L., Otani J.M., Galbraith D.A. Effects and blood concentrations of cobalt after ingestion of $1 \mathrm{mg} / \mathrm{d}$ by human volunteers for $90 \mathrm{~d}$. Am. J. Clin. Nutr., 2014, no. 99, pp. 632-646. DOI: 10.3945/ajen.113.071449

6. Unice K.M., Monnot A.D., Gaffney S.H., Tvermoes B.E., Thuett K.A., Paustenbach D.J., Finley B.L. Inorganic cobalt supplementation: Prediction of cobalt levels in whole blood and urine using a biokinetic model. Food and Chemical Toxicology, 2012, vol. 50, no. 7, pp. 2456-2461. DOI: 10.1016/j.fct.2012.04.009

7. Wei B., Yu J., Wang J., Li H., Yang L., Kong C. Trace Metals in the Urine and Hair of a Population in an Endemic Arsenism Area. Biol. Trace. Elem. Res., 2018, vol. 182, no. 2, pp. 209-216. DOI: 10.1007/s12011-017-1108-x

8. Simonsen L.O., Harbak H., Bennekou P. Cobalt metabolism and toxicology - a brief update. Sci. Total. Environ., 2012, vol. 432, pp. 210-215. DOI: 10.1016/j.scitotenv.2012.06.009

9. Ryuko S., Ma Y., Ma N., Sakaue M., Kuno T. Genome-wide screen reveals novel mechanisms for regulating cobalt uptake and detoxification in fission yeast. Mol. Genet. Genomics, 2012, vol. 287, no. 8, pp. 651-662. DOI: 10.1007/s00438-012-0705-9

10. Leyssens L., Vinck B., Van Der Straeten C., Wuyts F., Maes L. Cobalt toxicity in humans a review of the potential sources and systemic health effects. Toxicology, 2017, no. 387, pp. 43-56. DOI: $10.1016 /$ j.tox.2017.05.015

11. De Boeck M., Kirsch-Volders M., Lison D. Cobalt and antimony: genotoxicity and carcinogenicity. Mutat. Res., 2003, vol. 533, no. 1, 2, pp. 135-152. DOI: 10.1016/j.mrfmmm.2003.07.012 
12. Paustenbach D.J., Tvermoes B.E., Unice K.M., Finley B.L., Kerger B.D. A review of the health hazards posed by cobalt. Crit. Rev. Toxicol., 2013, vol. 43, no. 4, pp. 316-362. DOI: 10.3109/10408444.2013.779633

13. Liang Y., Zhen X., Wang K., Ma J. Folic acid attenuates cobalt chloride-induced PGE2 production in HUVECs via the NO/HIF-1alpha/COX-2 pathway. Biochem. Biophys. Res. Commun., 2017, vol. 490, no. 2, pp. 567-573. DOI: 10.1016/j.bbrc.2017.06.079

14. Yorita C.K.L. Metals in blood and urine, and thyroid function among adults in the United States 2007-2008. Int J. Hyg. Environ. Health, 2013, vol. 216, no. 6, pp. 624-632. DOI: 10.1016/j.ijheh.2012.08.005

15. Catalani S., Rizzetti M.C., Padovani A., Apostoli P. Neurotoxicity of cobalt. Hum. Exp. Toxicol., 2012, vol. 31, no. 5, pp. 421-437. DOI: 10.1177/0960327111414280

16. Dai Y., Li W., Zhong M., Chen J., Liu Y., Cheng Q., Li T. Preconditioning and posttreatment with cobalt chloride in rat model of perinatal hypoxic-ischemic encephalopathy. Brain Dev., 2014, vol. 36, no. 3, pp. 228-240. DOI: 10.1016/j.braindev.2013.04.007

17. Mendy A., Gasana J., Vieira E.R. Urinary heavy metals and associated medical conditions in the US adult population. Int. J. Environ. Health Res., 2012, vol. 22, no. 2, pp. 105-118. DOI: 10.1080/09603123.2011.605877

18. Yuan Y., Hilliard G., Ferguson T., Millhorn D.E. Cobalt inhibits the interaction between hypoxia-inducible factor-alpha and von Hippel-Lindau protein by direct binding to hypoxiainducible factor-alpha. J. Biol. Chem., 2003, vol. 278, no. 18, pp. 15911-15916. DOI: 10.74/jbc.M300463200

19. Maxwell P., Salnikow K. HIF-1: an oxygen and metal responsive transcription factor. Cancer Biol. Ther., 2004, vol. 3, no. 1, pp. 29-35. DOI: 10.4161/cbt.3.1.547

20. Jelkmann W. The Disparate Roles of Cobalt in Erythropoiesis, and Doping Relevance. Open Journal of Hematology, 2012, vol. 3, no. 1, pp. 3-6. DOI: 10.13055/ojhmt_3_1_6.121211

21. Muñoz-Sánchez J., Chánez-Cárdenas M.E. The use of cobalt chloride as a chemical hypoxia model. J. Appl. Toxicol., 2018, vol. 39, no. 4, pp. 1-15. DOI: 10.1002/jat.3749

22. Catalani S., Leone R., Rizzetti M.C., Padovani A., Apostoli P. The Role of Albumin in Human Toxicology of Cobalt: Contribution from a Clinical Case. ISRN Hematology, 2011, vol. 2011, 6 p. DOI: $10.5402 / 2011 / 690620$

23. Jomova K., Valko M. Advances in metal-induced oxidative stress and human disease. Toxicology, 2011, vol. 283, no. 2, 3, pp. 65-87. DOI: 10.1016/j.tox.2011.03.001

24. Zadnipryany I.V., Tretiakova O.S., Sataieva T.P., Zukow W. Experimental review of cobalt induced cardiomyopathy. Russian Open Medical Journal, 2017, vol. 6, no. 1, pp. 1-4. DOI: 10.15275/rusomj.2017.0103

25. Wang G., Hazra T.K., Mitra S., Lee H.M., Englander E.W. Mitochondrial DNA damage and a hypoxic response are induced by $\mathrm{CoCl}(2)$ in rat neuronal PC12 cells. Nucleic. Acids. Res., 2000, vol. 28 , no. 10, pp. 2135-2140. DOI: $10.1093 / \mathrm{nar} / 28.10 .2135$

26. Lee J.-H., Choi S.-H., Baek M.-W., Kim M.-H., Kim H.-J., Kim S.-H., Oh S.-J., Park H.-J. [et al.]. $\mathrm{CoCl} 2$ induces apoptosis through the mitochondria- and death receptor-mediated pathway in the mouse embryonic stem cells. Mol. Cell. Biochem., 2013, vol. 379, pp. 133-140. DOI: 10.1007/s11010-013-1635-5

27. K. Chamaon, P. Schönfeld, F. Awiszus, J. Bertrand, C.H. Lohmann. Ionic cobalt but not metal particles induces ROS generation in immune cells in vitro. J. Biomed. Mater. Res. B. Appl. Biomater., 2019, vol. 107, no. 4, pp. 1246-1253. DOI: 10.1002/jbm.b.34217

28. Lawrence H., Deeha D.J., Holland J.P., Anjum S.A., Mawdesley A.E., Kirby J.A., TysonCappera A.J. Cobalt ions recruit inflammatory cells in vitro through human Toll-like receptor-4. Biochem. Biophys. Rep., 2016, vol. 7, pp. 374-378. DOI: 10.1016/j.bbrep.2016.07.003

29. S.A. Anjum, H. Lawrence, J.P. Holland, J.A. Kirby, D.J. Deehan, A.J. Tyson Effect of cobaltmediated Toll-like receptor 4 activation on inflammatory responses in endothelial cells. Oncotarget, 2016, vol. 7, no. 47, pp. 76471-76478. DOI: 10.18632/oncotarget. 13260

30. Shweta, Mishra K.P., Chanda S., Singh S.B., Ganju L. A comparative immunological analysis of $\mathrm{CoCl} 2$ treated cells with in vitro hypoxic exposure. Biometals, 2015, vol. 28, no. 1, pp. 175-185. 
DOI: 10.1007/s10534-014-9813-9 31. Shrivastava K., Bansal A., Singh B., Sairam M., Ilavazhagan G. Sub-chronic oral toxicity study in Sprague-Dawley rats with hypoxia mimetic cobalt chloride towards the development of promising neutraceutical for oxygen deprivation. Exp. Toxicol. Pathol., 2010, vol. 62, no. 5, pp. 489-496. DOI: 10.1016/j.etp.2009.06.012

32. Liu Y., Xu H., Liu F., Tao R., Yin J. Effects of serum cobalt ion concentration on the liver, kidney and heart in mice. Orthopaedic Surgery, 2010, vol. 2, no. 2, pp. 134-140. DOI: 10.1111/j.17577861.2010.00076.x

33. Akinrinde A.S., Oyagbemi A.A., Omobowale T.O., Asenuga E.R., Ajibade T.O. Alterations in blood pressure, antioxidant status and caspase 8 expression in cobalt chloride-induced cardiorenal dysfunction are reversed by Ocimum gratissimum and gallic acid in Wistar rats. J. Trace. Elem. Med. Biol., 2016, no. 36, pp. 27-37. DOI: 10.1016/j.jtemb.2016.03.015

34. Feng W., Zhang Y., Deng H., Li S.J. Interaction of divalent metal ions with human translocase of inner membrane of mitochondria TIM23. Biochem. Biophys. Res. Commun., 2016, vol. 475, no. 1, pp. 76-80. DOI: 10.1016/j.bbrc.2016.05.039

35. Niu N., Li Z., Zhu M., Sun H., Yang J., Xu S., Zhao W., Song R. Effects of nuclear respiratory factor-1 on apoptosis and mitochondrial dysfunction induced by cobalt chloride in H9C2 cells. Molecular medicine reports, 2019, vol. 19, no. 3, pp. 2153-2163. DOI: 10.3892/mmr.2019.9839

36. Hantson P. Mechanisms of toxic cardiomyopathy. Clin. Toxicol., 2019, vol. 57, no. 1, pp. 1-9. DOI: $10.1080 / 15563650.2018 .1497172$

37. Kurhaluk N., Lukash O., Nosar V., Portnychenko A.G., Portnychenko V., WszedybylWinklewska M., Winklewski P.J. Liver mitochondrial respiratory plasticity and oxygen uptake evoked by cobalt chloride in rats with low and high resistance to extreme hypobaric hypoxia. Can. J. Physiol. Pharmacol., 2019, vol. 97, no. 5, pp. 392-399. DOI: 10.1139/cjpp-2018-0642

38. He Y., Gan X., Zhang L., Liu B., Zhu Z., Li T., Zhu J., Chen J., Yu H. CoCl2 induces apoptosis via a ROS-dependent pathway and Drp1-mediated mitochondria fission in periodontal ligament stem cells. Am. J. Physiol. Cell. Physiol., 2018, vol. 315, no. 3, pp. C389-C397. DOI: 10.1152/ajpcell.00248.2017

39. Saxena S., Shukla D., Bansal A. Augmentation of aerobic respiration and mitochondrial biogenesis in skeletal muscle by hypoxia preconditioning with cobalt chloride. Toxicol. Appl. Pharmacol., 2012, vol. 264, no. 3, pp. 324-334. DOI: 10.1016/j.taap.2012.08.033

40. Liu Y., Hong H., Lu X., Wang W., Liu F., Yang H.L. L-Ascorbic Acid Protected Against Extrinsic and Intrinsic Apoptosis Induced by Cobalt Nanoparticles Through ROS Attenuation. Biol. Trace. Elem. Res., 2017, vol. 175, no. 2, pp. 428-439. DOI: 10.1007/s12011-016-0789-x

41. Ebert B., Jelkmann W. Intolerability of cobalt salt as erythropoietic agent. Drug. Test. Anal., 2014, vol. 6, no. 3, pp. 185-189. DOI: 10.1002/dta.1528

42. Hoffmeister T., Schwenke D., Wachsmuth N., Krug O., Thevis M., Byrnes W.C., Schmidt W.F.J. Erythropoietic effects of low-dose cobalt application. Drug. Test. Anal., 2019, vol. 11, no. 2, pp. 200-207. DOI: $10.1002 / \mathrm{dta} .2478$

43. Karaczyn A., Ivanov S., Reynolds M., Zhitkovich A., Kasprzak K.S., Salnikow K. Ascorbate depletion mediates up-regulation of hypoxia-associated proteins by cell density and nickel. J. Cell. Biochem., 2006, vol. 97, no. 5, pp. 1025-1035. DOI: 10.1002/jcb.20705

44. Kaczmarek M., Cachau R.E., Topol I.A., Kasprzak K.S., Ghio A., Salnikow K. Metal ionsstimulated iron oxidation in hydroxylases facilitates stabilization of HIF-1 alpha protein. Toxicol. Sci., 2009, vol. 107, no. 2, pp. 394-403. DOI: 10.1093/toxsci/kfn251

45. Yuan Y., Hilliard G., Ferguson T., Millhorn D.E. Cobalt inhibits the interaction between hypoxia-inducible factor-alpha and von Hippel-Lindau protein by direct binding to hypoxiainducible factor-alpha. J. Biol. Chem., 2003, vol. 278, no. 18, pp. 15911-15916. DOI: 10.74/jbc.M300463200

46. Shrivastava K., Ram M.S., Bansal A., Singh S.S., Ilavazhagan G. Cobalt supplementation promotes hypoxic tolerance and facilitates acclimatization to hypobaric hypoxia in rat brain. High. Alt. Med. Biol., 2008, vol. 9, no. 1, pp. 63-75. DOI: 10.1089/ham.2008.1046 
47. Jeon E.S., Shin J.H., Hwang S.J., Moon G.J., Bang O.Y., Kim H.H. Cobalt chloride induces neuronal differentiation of human mesenchymal stem cells through upregulation of microRNA-124a. Biochem. Biophys. Res. Commun., 2014, vol. 444, no. 4, pp. 581-587. DOI: 10.1016/j.bbrc.2014.01.114

48. Chai Y.C., Mendes L.F., Van Gastel N., Carmeliet G., Luyten F.P. Fine-tuning proangiogenic effects of cobalt for simultaneous enhancement of vascular endothelial growth factor secretion and implant neovascularization. Acta Biomater., 2018, no. 72, pp. 447-460. DOI: 10.1016/j.actbio.2018.03.048

49. Chen Y., Zhao Q., Yang X., Yu X., Yu D., Zhao W. Effects of cobalt chloride on the stem cell marker expression and osteogenic differentiation of stem cells from human exfoliated deciduous teeth. Cell. Stress. Chaperones., 2019, vol. 24, no. 3, pp. 527-538. DOI: 10.1007/s12192-019-00981-5

50. Matsumoto M., Makino Y., Tanaka T., Tanaka H., Ishizaka N., Noiri E., Fujita T., Nangaku M. Induction of Renoprotective Gene Expression by Cobalt Ameliorates Ischemic Injury of the Kidney in Rats. J. Am. Soc. Nephrol., 2003, no. 14, pp. 1825-1832.

51. Tanaka T., Kojima I., Ohse T., Ingelfinger J.R., Adler S., Fujita T., Nangaku M. Cobalt promotes angiogenesis via hypoxia-inducible factor and protects tubulointerstitium in the remnant kidney model. Laboratory Investigation, 2005, no. 85, pp. 1292-1307. DOI: 10.1038/labinvest.3700328

52. Oyagbemi A.A., Omobowale T.O., Awoyomi O.V., Ajibade T.O., Falayi O.O., Ogunpolu B.S., Okotie U.J., Asenuga E.R. [et al.]. Cobalt chloride toxicity elicited hypertension and cardiac complication via induction of oxidative stress and upregulation of COX-2/Bax signaling pathway. Hum. Exp. Toxicol., 2019, vol. 38, no. 5, pp. 519-532. DOI: 10.1177/0960327118812158

53. Kong D., Zhang F., Shao J., Wu L., Zhang X., Chen L., Lu Y., Zheng S. Curcumin inhibits cobalt chloride-induced epithelial-to-mesenchymal transition associated with interference with TGF$\beta /$ Smad signaling in hepatocytes. Lab. Invest., 2015, vol. 95, no. 11, pp. 1234-1245. DOI: 10.1038/labinvest.2015.107

54. Czarnek K., Terpiłowska S., Siwicki A.K. Selected aspects of the action of cobalt ions in the human body. Cent. Eur. J. Immunol., 2015, vol. 40, no. 2, pp. 236-242. DOI: 10.5114/ceji.2015.52837

55. Nagasawa H. Pathophysiological response to hypoxia - from the molecular mechanisms of malady to drug discovery: drug discovery for targeting the tumor microenvironment. J. Pharmacol. Sci., 2011, vol. 115, no. 4, pp. 446-452.

56. Eskandani M., Vandghanooni S., Barar J., Nazemiyeh H., Omidi Y. Cell physiology regulation by hypoxia inducible factor-1: Targeting oxygen-related nanomachineries of hypoxic cells. Int J. Biol. Macromol., 2017, no. 99, pp. 46-62. DOI: 10.1016/j.ijbiomac.2016.10.113

57. Liang Y., Zhen X., Wang K., Ma J. Folic acid attenuates cobalt chloride-induced PGE2 production in HUVECs via the NO/HIF-1alpha/COX-2 pathway. Biochem. Biophys. Res. Commun., 2017, vol. 490, no. 2, pp. 567-573. DOI: 10.1016/j.bbrc.2017.06.079

58. Schmidt M., Raghavan B., Müller V., Vogl T., Fejer G., Tchaptchet S., Keck S., Kalis C. [et al.]. Crucial role for human Toll-like receptor 4 in the development of contact allergy to nickel. Nat. Immunol., 2010, vol. 11, no. 9, pp. 814-819. DOI: 10.1038/ni.1919

59. Samelko L., Landgraeber S., McAllister K., Jacobs J., Hallab N.J. Cobalt Alloy Implant Debris Induces Inflammation and Bone Loss Primarily through Danger Signaling, Not TLR4 Activation: Implications for DAMP-ening Implant Related Inflammation. PLOS ONE, 2016, vol. 11, no. 7, pp. e0160141. DOI: 10.1371/journal.pone.0160141

60. Kwak J., Choi S.J., Oh W., Yang Y.S., Jeon H.B., Jeon E.S. Cobalt Chloride Enhances the Anti-Inflammatory Potency of Human Umbilical Cord Blood-Derived Mesenchymal Stem Cells through the ERK-HIF-1 $\alpha$-MicroRNA-146a-Mediated Signaling Pathway. Stem. Cells International, 2018, vol. 2018, 12 p. DOI: 10.1155/2018/4978763

61. Xu J., Nyga A., Li W., Zhang X., Gavara N., Knight M.M., Shelton J.C. Cobalt ions stimulate a fibrotic response through matrix remodelling, fibroblast contraction and release of pro-fibrotic signals from macrophages. European Cells and Materials, 2018, no. 36, pp. 142-155. DOI: 10.22203/eCM.v036a11 
62. Ratha S., Dasa L., Kokatea S., Ghosha N., Dixita P., Routb N., Singhc S.P., Chattopadhyaya S. [et al.]. Inhibition of histone/lysine acetyltransferase activity kills CoCl2-treated and hypoxia-exposed gastric cancer cells and reduces their invasiveness. Int J. Biochem. Cell. Biol., 2017, no. 82, pp. 28-40. DOI: 10.1016/j.biocel.2016.11.014

63. Li C.-L., Xu Z.-B., Fan X.-L., Chen H.-X., Yu Q.-N., Fang S.-B., Wang S.-Y., Lin Y.-D., Fu Q.-L. MicroRNA-21 Mediates the Protective Effects of Mesenchymal Stem Cells Derived from iPSCs to Human Bronchial Epithelial Cell Injury Under Hypoxia. Cell. Transplantation., 2018, vol. 27, no. 3, pp. 571-583. DOI: 10.1177/0963689718767159

64. Permenter M.G., Dennis W.E., Sutto T.E., Jackson D.A., Lewis J.A. [et al.]. Exposure to Cobalt Causes Transcriptomic and Proteomic Changes in Two Rat Liver Derived Cell Lines. PLoS ONE, 2013, vol. 8, no. 12, pp. e83751. DOI: 10.1371/journal.pone.0083751

65. Salnikow K., Zhitkovich A. Genetic and Epigenetic Mechanisms in Metal Carcinogenesis and Cocarcinogenesis: Nickel, Arsenic and Chromium. Chem. Res. Toxicol., 2008, vol. 21, no. 1, pp. $28-44$. DOI: $10.1021 /$ tx700198a

66. Salnikow K., Aprelikova O., Ivanov S., Tackett S., Kaczmarek M., Karaczyn A., Yee H., Kasprzak K.S., Niederhuber J. Regulation of hypoxia-inducible genes by ETS1 transcription factor. Carcinogenesis, 2008, vol. 29, no. 8, pp. 1493-1499. DOI: 10.1093/carcin/bgn088

67. Chervona Y., Costa M. The control of histone methylation and gene expression by oxidative stress, hypoxia and metals. Free Radic. Biol. Med., 2012, vol. 53, no. 5, pp. 1041-1047. DOI: 10.1016/j.freeradbiomed.2012.07.020

68. Brocato J., Costa M. Basic Mechanics of DNA Methylation and the Unique Landscape of the DNA Methylome in Metal-Induced Carcinogenesis. Crit. Rev. Toxicol., 2013, vol. 43, no. 6, pp. 493-514. DOI: 10.3109/10408444.2013.794769

69. Bae S., Jeong H.-J., Cha H.J., Kim K., Choi Y.M., An I.-S., Koh H.J., Lim D.J. [et al.]. The hypoxia-mimetic agent cobalt chloride induces cell cycle arrest and alters gene expression in U266 multiple myeloma cells. International journal of molecular medicine, 2012, no. 30, pp. 1180-1186. DOI: $10.3892 /$ ijmm.2012.1115

70. Hattori S., Kamiya T., Hara H., Ninomiya M., Koketsu M., Adach T. CoCl2 Decreases EC-SOD Expression through Histone Deacetylation in COS7 Cells. Biol. Pharm. Bull., 2016, vol. 39, no. 12, pp. 2036-2041. DOI: 10.1248/bpb.b16-00551

71. Chen R., Jiang T., She Y., Xu J., Li C., Zhou S., Shen H., Shi H., Liu S. Effects of Cobalt Chloride, a Hypoxia-Mimetic Agent, on Autophagy and Atrophy in Skeletal C2C12 Myotubes. Biomed. Res. Int., 2017, no. 7097580. DOI: 10.1155/2017/7097580

72. Tan L., Lai X., Zhang M., Zeng T., Liu Y., Deng X., Qiu M., Li J. [et al.]. A stimuli-responsive drug release nanoplatform for kidney-specific anti-fibrosis treatment. Biomater. Sci., 2019, vol. 7, no. 4, pp. 1554-1564. DOI: $10.1039 / \mathrm{c} 8 \mathrm{bm} 01297 \mathrm{k}$

73. Stenger C., Naves T., Verdier M., Ratinaud M.H. The cell death response to the ROS inducer, cobalt chloride, in neuroblastoma cell lines according to p53 status. Int J. Oncol., 2011, vol. 39, no. 3, pp. 601-609. DOI: 10.3892/ijo.2011.1083

74. Chimeh U., Zimmerman M.A., Gilyazova N., Li P.A. B355252, A Novel Small Molecule, Confers Neuroprotection Against Cobalt Chloride Toxicity In Mouse Hippocampal Cells Through Altering Mitochondrial Dynamics And Limiting Autophagy Induction. Int J. Med. Sci., 2018, vol. 15, no. 12, pp. 1384-1396. DOI: 10.7150/ijms.24702

75. Kumanto M., Paukkeri E.-L., Nieminen R., Moilanen E. Cobalt (II) Chloride Modifies the Phenotype of Macrophage Activation. Basic \& Clinical Pharmacology \& Toxicology, 2017, no. 121, pp. 98-105. DOI: 10.1111/bcpt.12773

76. Luo H.-M., Du M.-H., Lin Z.-L., Zhang L., Ma L. [et al.]. Valproic Acid Treatment Inhibits Hypoxia-Inducible Factor $1 \alpha$ Accumulation and Protects against Burn-Induced Gut Barrier Dysfunction in a Rodent Model. PLoS ONE, 2013, vol. 8, no. 10, pp. e77523. DOI: 10.1371/journal.pone.0077523

77. Kim Y.J., Park S.J., Kim N.R., Chin H.S. Effects of Histone Deacetylase Inhibitor (Valproic Acid) on the Expression of Hypoxia-inducibleFactor-1 Alpha in Human Retinal Müller Cells. Korean J. Ophthalmol., 2017, vol. 31, no. 1, pp. 80-85. DOI: 10.3341/kjo.2017.31.1.80 
78. Ho J.J., Metcalf J.L., Yan M.S., Turgeon P.J., Wang J.J., Chalsev M., PetruzzielloPellegrini T.N., Tsui A.K. [et al.]. Functional importance of Dicer protein in the adaptive cellular response to hypoxia. J. Biol. Chem., 2012, vol. 287, no. 34, pp. 29003-29020. DOI: 10.1074/jbc.M112.373365

Dolomatov S.I., Sataeva T.P., Zukow W. Modern aspects of regulatory, pathophysiological and toxic effects of cobalt ions during oral intake in the human body. Health Risk Analysis, 2019, no. 3, pp. 161-174. DOI: 10.21668/health.risk/2019.3.19.eng

Received: 21.05 .2019

Accepted: 26.07.2019

Published: 30.09.2019 